\title{
Monitoring of Pupils' Imagination within the Framework of Creativity Formation Program
}

\section{Anatoly Maslak}

Branch of Kuban State University at Slavyansk-on-Kuban, 200 Kubanskaya str. Slavyansk-on-Kuban Krasnodar Krai, Russia 353560; natoliy_maslak@mail.ru

\section{Alexey Rybkin}

Branch of Kuban State University at Slavyansk-on-Kuban, 200 Kubanskaya str. Slavyansk-on-Kuban Krasnodar Krai, Russia 353560; aleksrybk@yandex.ru

Tatijana Anisimova

Branch of Kuban State University at Slavyansk-on-Kuban, 200 Kubanskaya str. Slavyansk-on-Kuban Krasnodar Krai, Russia 353560; anisimova_ts@mail.ru

\section{Stanislav Pozdniakov}

Branch of Kuban State University at Slavyansk-on-Kuban, 200 Kubanskaya str. Slavyansk-on-Kuban Krasnodar Krai, Russia 353560; pozdnyakov_sta@mail.ru

\section{Doi:10.5901/mjss.2015.v6n6s5p234}

\section{Abstract}

The investigation purpose of this research is to monitor the level of imagination of pupils in the fifth grade as a result of implementation of the creativity formation program. The urgency of this research is caused by the fact that imagination is unimportant component of creativity. The research was conducted within the framework of the theory of measurement of latent variables based on the Rasch model. It is shown that the questionnaire possesses good differentiating ability and corresponds to the levels of pupils' imagination. Measurement of pupils' imagination on the linear scale allows to quantitatively estimate in detail the efficiency of the creativity formation program. As a result of implementation of the creativity formation program, the level of pupils' imagination has increased. Results of ANOVA have shown that the level of imagination of girls has risen more than level of imagination of boys. The creativity formation program has appeared more interesting for girls than for boys. So the creativity formation program should be revised- it should be interesting not only for girls, but also for boys. For increasing the precision of measurement of level of imagination there is a need to increase number of indicators.

Keywords: imagination, creativity, monitoring, Rasch measurement.

\section{Introduction}

Development of creative abilities of pupils is dictated by the present stage of development of education system and society. Creativity, more than ever, is the competitive advantage of the human brain. Individuals without creativity will be left behind in a world in which non-creative thought can be automated, but creative solutions to problems are at a premium (Abbott, 2010). Today it is inexpedient to teach the person to do work with which it is possible to replace with machine work. Therefore, special attention is given to the development of creative and creative thinking. Imagination is one of the main aspects of the creativity.

There are many Russian and foreign scientists devoted to studying broad aspects of creativity - its essence, importance, formation, connections with other traits, estimation and many others (Beghetto, 2013; Epstein, 2012; Starko, 2014; Tunik, 2002). Valuable contribution to the development of both theory and practice of creative training were made by R.A. Begetto (2013) and A.I. Starko (2014).For more profound research of creativity there is a need in quantitative estimation of this construct (latent variable). Some aspects of this trait were measured within the framework of the theory of latent variables (Maslak \& Rybkin, 2014).

Imagination is an important component of creativity and, in large degree, defines the creativity. Therefore, formation, measurement, and monitoring of pupils' imagination is an important task. 


\section{Objectives}

The purpose of this investigation is to establish a unidimensional interval scale for latent variable "imagination" in order to measure and monitor pupils' imagination before and after the implementation of the creativity formation program. The developed program was used in secondary school for $5^{\text {th }}$ grade pupils during geography and history classes (Rybkin, 2015).

\section{Research Question}

For achievement of the given purpose it is necessary to:

- Explore the possibility that indicators (items) of questionnaire coherently define a latent trait "imagination" with linear measurement properties;

- Measure on a linear scale the level of development of pupils' imagination before and after creativity program implementation;

- Carry out multifactor analysis of variance of the estimates of pupils' imagination before and after the implementation of the creativity program;

- Consider factors influencing pupils' imagination.

\section{Methodology and Research Design}

Pupils' imagination was measured by means of the same questionnaire before and after implementation of the creativity formation program. Initially the questionnaire consisted of twelve items (Tunik, 2002). Table 1presents this questionnaire.

Table 1. Indicators of questionnaire

\begin{tabular}{cl}
\hline No & Indicators \\
\hline 1 & I like to consider a subject in detail to find out details which did not see earlier \\
2 & Usually I ask questions if I do not know something \\
3 & I like to be engaged in something new \\
4 & I like to make new friends \\
5 & I often try to imagine what other people think \\
6 & There are a lot of things with which I would like to experiment \\
7 & If I have found the answer to a question once, I will adhere to it, instead of searching for other answers \\
8 & I like to investigate old suitcases and boxes simply to look at their content \\
9 & It is interesting to solve puzzles and play games in which it is necessary to predict further steps \\
10 & I am interested indifferent mechanisms; I like to analyze at how they work \\
11 & I like to thumb through books and magazines simply to look at them \\
12 & I like to ask questions about things on which other people do not reflect
\end{tabular}

The pupils were asked to rate the degree of agreement with each item; the rating criteria was a four point Likert scale:

\section{$3=$ Strongly Agree}

$2=$ Agree

$1=$ Neutral

$0=$ Disagree

In the survey 80 5-grade pupils of the secondary school were used.

Measurement of pupils' imagination was carried out within the framework of the theory of latent variables based on Rasch model (Rasch, 1960). This method has well proved itself at the decision of many problems in social systems (Maslak et. al., 2005; Maslak \& Rybkin, 2014).

Data of the survey was transformed to linear measures with a Rasch model for rating scales, which computes a log-odds transformation of indicators and objects (pupils), then computes differences between indicators and objects also guided by the one-parameter logistic function to establish a common dimension (Wright and Masters, 1982). A simple mathematical model is implemented for this transformation: 


$$
\Pi_{\text {nix }}=\frac{\exp _{j=0}^{x}\left[\beta_{n}-\left(\delta_{i}+\tau_{j}\right)\right]}{\sum_{k=0}^{m} \exp _{j=0}^{k}\left[\beta_{n}-\left(\delta_{i}+\tau_{j}\right)\right]}
$$

Where $\beta_{n}=$ object's location parameter on the imagination latent trait,

$\delta_{\mathrm{i}}=$ indicator location parameter on the latent trait, and

$\tau=$ rating scale thresholds.

חnixis the probability that any indicator $\delta_{i}$ will be coded $X$ for any object $\beta_{n}$ where $X$ takes a value from a fixed range $(j=0,1,2,3), m=$ number of steps for an indicator, and $k=$ ith step. The conformability of raw data to mathematical expectations was assessed with a Chi-square derived fit analysis of indicator and institutions residuals (Wright \& Masters, 1982).

For data processing RUMM2020 software was used (Andrich et. al., 2005).

The priority when measuring a latent variable was the estimation of quality of the measuring tool, namely compatibility of items. This is checked on the basis of the Chi-square criterion. Several initial runs of Rasch analysis were performed and two indicators (item 2 "Usually I ask questions if I do not know something" and item 8 "I like to investigate old suitcases and boxes simply to look their content") were incompatible with Rasch model and were excluded from the questionnaire.

\section{Results of the Analysis and Discussion}

It has appeared that the empirical value of the Chi-square statistics of the remained indicators surpasses nominal value 0.05 that proves the compatibility of a set of items and its applicability for measurement of a latent variable "imagination".

\subsection{Characteristic of the questionnaire as a measuring tool}

Table 2 presents statistical characteristics of items. Items in this table are ordered on their location (the second column) on the scale "imagination" - from the least value (-0.316 logit) to the greatest (+0.855 logit). Standard error characterizes the precision of item estimation (the third column). The fourth and fifth columns contain the Chi-square statistics and its empirical significance.

Table 2. Statistical characteristics of items

\begin{tabular}{|c|c|c|c|c|}
\hline Item & Location (logit) & Standard error (logit) & Chi-Square statistic & Sig. (p) \\
\hline 10 & $-0,316$ & 0,083 & 5,229 & 0,073 \\
\hline 9 & $-0,273$ & 0,081 & 2,143 & 0,342 \\
\hline 11 & $-0,205$ & 0,079 & 4,300 & 0,112 \\
\hline 5 & $-0,190$ & 0,077 & 3,441 & 0,179 \\
\hline 4 & $-0,120$ & 0,076 & 4,012 & 0,135 \\
\hline 7 & $-0,032$ & 0,073 & 2,286 & 0,319 \\
\hline 1 & 0,002 & 0,076 & 2,133 & 0,344 \\
\hline 6 & 0,278 & 0,073 & 0,074 & 0,964 \\
\hline 3 & 0,859 & 0,081 & 3,037 & 0,265 \\
\hline
\end{tabular}

Source: Own analysis

As can be seen in Table 2, all indicators have a significance value of more than 0,05 . Therefore, it is possible to draw a conclusion that all indicators are compatible, and this set of indicators can be considered as a tool for measuring pupils' imagination.

It is of interest to consider two distinct items: the "easiest" and the most "difficult".

Graph 1 elaborates the results of the "easiest" indicator 10 "I am interested in mechanisms; I like to analyze at how they work", which has a chi-square fit statistic having a p-value of 0,090. The "easiest" indicator is the indicator that differentiates pupils with low level of imagination better than others. This is confirmed by low value of location of the indicator (-0,333 logits). 
Graph 1. Item characteristic curve for the "easiest" indicator 10 "I am interested in mechanisms; I like to analyze at how they work"

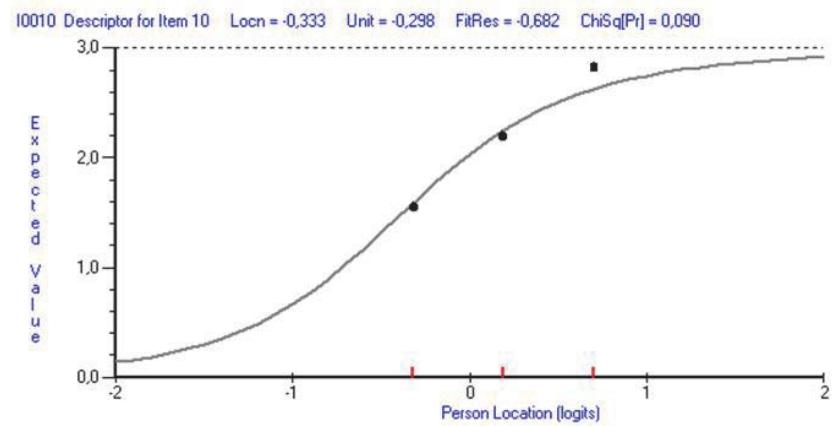

Source: Own analysis

The structure of this and other similar figures is described in detail in (Andrich et. al., 2005). In graph 1, each of the three points represents the mean response of pupils on indicator 10 "I am interested in mechanisms; l like to analyze at how they work", with respect to the "low", "medium," and "high" category on the $\beta$ scale, respectively. Recall that $\beta$ represents a measure of imagination. The line in the Figure 1 represents the predicted response of the Rasch model, as a function of $\beta$, in other words, the estimated item characteristic curve (ICC). new".

Graph 2 presents the mean responses, and the estimated ICC for indicator 3 "I like to be engaged in something

Graph 2. Item characteristic curve for the most "difficult" indicator 3 "I like to be engaged in something new"

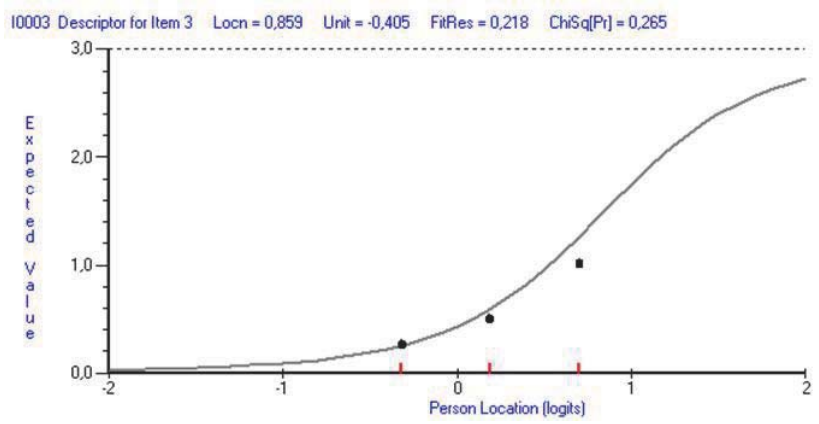

Source: Own analysis

The most "difficult" indicator differentiates pupils with a high level of imaginationbetter than other indicators. The location of the location of this indicator has the highest value (0,859 logits).

\subsection{Illustration results of measurement}

Graph 3 presents a map of indicators and objects after transformation to a common dimension. 
Graph 3. Map of estimates of pupils and indicators on the scale "imagination"

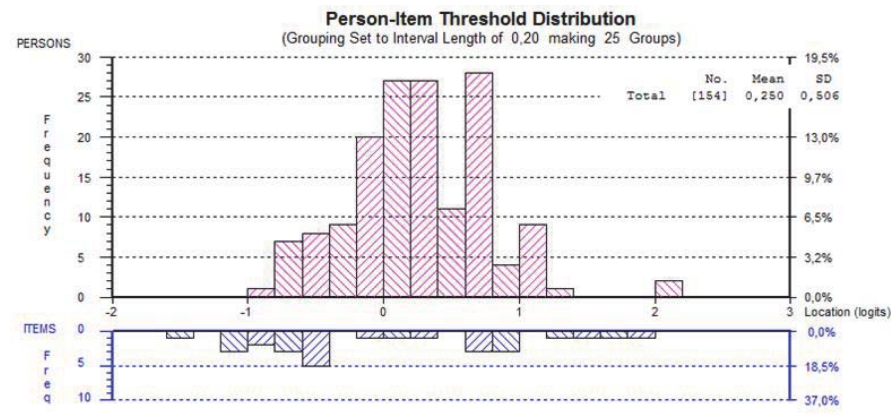

Source: Own analysis

In graph 3, persons correspond to pupils and items correspond to indicators. These results show that indicators defining imagination well-targeted on pupils without ceiling or floor effects.

Indicators, in general, appear to distribute well across the latent trait. Results show that indicators targeted the objects with a range between $-1,50$ and 2,00 logits, $S D=0,37$. Estimates of pupils' imagination distribute from $-1,00$ to 2,00 logits. Mean estimate of pupils' imagination equals to $0,25, S D=0,51$. Although data variability is modest, $S D=$ 0,51 , object separation index is high and equals 0,75 .

\subsection{Analysis of factors influencing pupils' imagination}

According to the research objective, we will consider factors that influence pupils' imagination.

- Factor A - efficiency of the creativity formation program which is estimated as a difference of pupils' imagination after and before the implementation of the program. In statistical terms the factor varies at two levels (before implementation of the program and after implementation of the program).

- Factor B, - class, - varies at three levels (5A, 5D, and 5 C classes);

- Factor $C$, - gender of the pupil, - varies at two levels (girl and boy).

The response (target parameter) $Y$ is pupils' imagination.

All these factors are qualitative ones, so for processing of results of the survey analysis of variance was used. Results of the ANOVA three-way based on three-way complete model are presented in Table 3.

Table 3. Results of three-way ANOVA of pupils' imagination

\begin{tabular}{cccccc}
\hline Source of variation & Sum of squares & Degrees of freedom & Mean sum of squares & F & Sig.(p) \\
\hline Factor A & 1,029 & 1 & 1,029 & 4,229 & 0,042 \\
Factor B & 0,107 & 2 & 0,053 & 0,220 & 0,803 \\
Factor C & 0,218 & 1 & 0,218 & 0,894 & 0,346 \\
Interaction AB & 0,379 & 2 & 0,189 & 0,779 & 0,461 \\
Interaction AC & 2,289 & 1 & 2,289 & 9,408 & 0,003 \\
Interaction BC & 0,421 & 2 & 0,210 & 0,865 & 0,423 \\
Interaction ABC & 0,620 & 2 & 0,310 & 1,273 & 0,283 \\
Error & 34,556 & 142 & 0,243 & & \\
Total & 39,228 & 153 & & & \\
\hline
\end{tabular}

Source: Own analysis

The results presented in Table 3 show that in this investigation the most important source of variance, factor $A$, is statistically significant $(p=0,042<0,05)$.It proves the effectiveness of the developed creativity formation program. Table 4 presents pupils' imagination estimates before and after the implementation of creativity formation program. 
Table 4. Mean values of pupils' imagination before and after the implementation of creativity formation program

\begin{tabular}{|c|c|c|c|c|}
\hline Factor $\mathrm{A}$ & Level of imagination (logits) & Standard error (logits) & $\begin{array}{r}95 \% \text { con } \\
\text { Low boundar }\end{array}$ & $\begin{array}{l}\text { ence interval } \\
\text { Upper boundary }\end{array}$ \\
\hline Before program implementation & 0,161 & 0,059 & 0,045 & 0,277 \\
\hline After program implementation & 0,327 & 0,056 & 0,217 & 0,438 \\
\hline
\end{tabular}

Source: Own analysis

Pupils' imagination estimates have increased after implementation of the creativity formation program from 0,161 logits to 0,327 logits.

Factor $B$ (class) is nonsignificant ( $p=0,803>0,05)$. Table 5 presents results of measurement of pupils' imagination estimates depending on class.

Table 5. Mean values of pupils' imagination estimates depending on class

\begin{tabular}{ccccc}
\hline Factor B & Level of imagination (logits) & Standard error (logits) & \multicolumn{2}{c}{$95 \%$ confidence interval } \\
Low boundary & Upper boundary \\
\hline Class 5A & 0,236 & 0,070 & 0,098 & 0,374 \\
Class 5B & 0,280 & 0,069 & 0,143 & 0,417 \\
Class 5C & 0,216 & 0,071 & 0,075 & 0,357 \\
\hline
\end{tabular}

Source: Own analysis

As it can be seen from Table 5 classes differ from each other. Pupils of the class $5 B$ have the highest level of imagination $(0,280$ logits), pupils of the class $5 \mathrm{C}$ have the least level of imagination $(0,216$ logits), but this difference is statistically insignificant. Table 6 presents results of measurement of pupils' imagination estimates depending on their gender.

Table 6. Mean values of pupils' imagination estimates depending on their gender

\begin{tabular}{ccccc}
\hline Factor C & Level of imagination (logits) & Standard error (logits) & \multicolumn{2}{c}{$95 \%$ confidence interval } \\
Low boundary & Upper boundary \\
\hline Male & 0,282 & 0,053 & 0,178 & 0,387 \\
Female & 0,206 & 0,062 & 0,084 & 0,327 \\
\hline
\end{tabular}

Source: Own analysis

Table 6 shows that, on average, boys have a higher level of imagination $(0,282$ logits) than girls $(0,206$ logits), but this difference is non significant. A very interesting finding in the investigation is the significance of the interaction AC. It means that the effect of the creativity formation program depends on gender of pupils (Table 7).

Table 7. Mean estimates of pupils' imagination depending on their gender and effect of the creativity formation program (interaction $\mathrm{AC}$ )

\begin{tabular}{|c|c|c|c|c|c|}
\hline \multirow{2}{*}{ Factor A } & \multirow{2}{*}{ Factor C } & \multirow{2}{*}{\begin{tabular}{|c|} 
Level of imagination \\
(logits)
\end{tabular}} & \multirow{2}{*}{ Standard error (logits) } & \multicolumn{2}{|c|}{\begin{tabular}{|l|}
$95 \%$ confidence interval \\
\end{tabular}} \\
\hline & & & & Low boundary & Upper boundary \\
\hline \multirow{2}{*}{ Before program implementation } & Boys & 0,323 & 0,076 & 0,173 & 0,473 \\
\hline & Girls & $-0,002$ & 0,089 & $-0,178$ & 0,174 \\
\hline \multirow{2}{*}{ After program implementation } & Boys & 0,241 & 0,073 & 0,097 & 0,386 \\
\hline & Girls & 0,413 & 0,085 & 0,246 & 0,581 \\
\hline
\end{tabular}

Source: Own analysis

Data in Table 7 reveal inconsistent dynamics. On the one hand, there is the considerable growth of imagination of girls (from -0,002 to 0,413 logits), and on the other hand - a small decrease of imagination of boys (from 0,323 to 0,241 logits). Illustration of this effect is shown in graph 4. 
Graph 4. Effect of the creativity formation program on girls and boys (interaction AC)

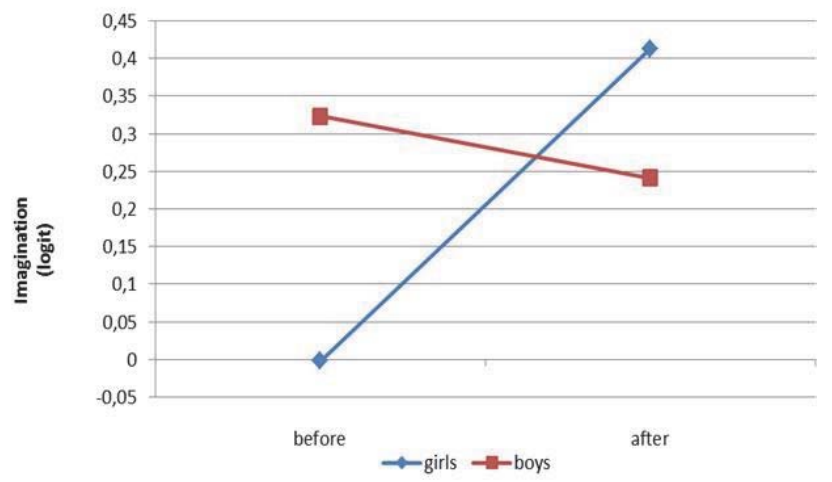

Source: Own analysis

As it can be seen from the graph 4 , the effect of the creativity formation program depends on gender of the pupils. The imagination of girls increase but imagination of boys decreases in some degree. A possible explanation of this effect is that the developed creativity formation program is of more interest for girls, than for boys. But as a whole the program has shown its efficiency.

\section{Conclusion}

This research appears to be the first attempt to construct a unidimensional linear scale for trait "imagination". Compared with the approach of evaluating imagination by interpreting raw observations on indicators, the Rasch model approach to measuring imagination has several important advantages. Firstly, a single measure of trait imagination can be constructed from a large number of different indicators. Secondly, the estimated Rasch measures are on a linear scale, so it is possible to quantitatively compare and monitor pupils, classes, schools, etc. Thirdly, more indicators lead to greater precision of measurement of the trait. Lastly, the estimated measures are successfully used for efficiency estimation of the developed creativity formation program, and for providing information useful for making decisions in school educational policy.

\section{Acknowledgements}

We would like to extend our sincere thanks to the Branch of Kuban State University at Slavyansk-on-Kuban for providing the resources necessary for conducting this research. Without its support this research could not have been conducted.

\section{References}

Abbott, D.H. (2010). Constructing a creative self-efficacy inventory: a mixed methods inquiry. Dissertation. University of Nebraska.

Andrich, D., Sheridan, B., and Luo, G. (2005). RUMM 2020: Rasch Unidimensional Measurement Models software and manual. Perth, Australia: RUMM Laboratory.

Beghetto, R.A. (2013). Killing ideas softly? The promise and perils of creativity in the classroom. Information Age Publishing, Inc., Charlotte, NC.

Epstein, R.V. (2012). Which competencies are most important for creative expression? Creativity research Journal, 24 (4), $278-282$.

Maslak, A.A., Karabatsos, G., Anisimova, T.S., and Osipov, S.A. (2005). Measuring and Comparing Higher Education Quality between Counties Worldwide. Journal of Applied Measurement, V.6, N. 4, 432-442.

Maslak, A. A, and Rybkin, A. D.(2014). Analiz kachestva oprosnika dlya izmereniya na lineynoy shkale lyuboznatelnosti shkol'nikov [Analysis of quality of a questionnaire for measurement on a linear scale ofpupils' curiosity]. Pedagogicheskoe obrazovanie $v$ Rossii, 12, 158-165.

Rasch, G. (1960). Probabilistic models for some intelligence and attainment tests. Copenhagen, Denmark: Danish Institute for Educational Research. (Expanded edition, 1980. Chicago: University of Chicago Press.) 
Rybkin, A.D.(2015). Osobennosti primeneniya metodov razvitiya kreativnih sposobnostey lichnosti na urokah istorii v sredney shkole [Technique of pupils' creativity development at lessons of history in high school]. Mezhdunarodniy nauchniy zhurnal "Innovacionnaya nauka", 8, 138-142.

Starko, A.J. (2014). Creativity in the classroom. Fifth edition. Routledge, New York, NY.

Wright, B.D. and Masters, G.N. (1982). Rating Scale Analysis. Chicago: MESA Press.

Tunik, E.E. (2002). Diagnostika lichnostnoy kreativnosti [Diagnostics of creativity of person] In Fetiskin, N.P., Kozlov, V.V., Manuylov, G. M. (Eds.) Socialno-psihologicheskaya diagnostika razvitiya lichnosti i malih group. Moskva: Izdatel’stvo Instituta Psihoterapii, 4252. 